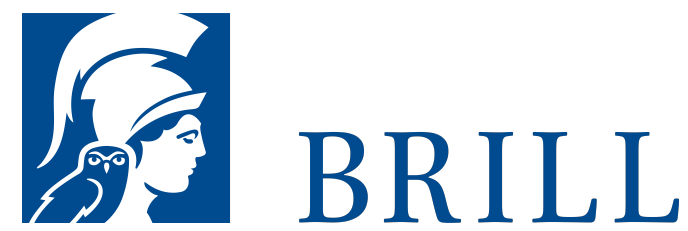

\title{
Zwischen Bilderlast und Bilderschatz
}

Pressefotografie und Bildarchive im Zeitalter der Digitalisierung

Author: Mirco Melone

Digitalisierung macht Geschichte: Öffentliche Institutionen übernehmen vermehrt Fotobestände von Bildagenturen und codieren sie zu historischen Kulturgütern um. Doch das ist bloss das vorläufige Ende eines vielschichtigen historischen Prozesses. Basierend auf einer historischen Ethnografie des Fotoarchivs des Schweizer Ringier-Verlags geraten Akteure, archivarische Praktiken und institutionelle Logiken unter die Lupe. Sie geben den mannigfaltigen Digitalisierungsprozessen von Fotografien seit den 197oer-Jahren Kontur. Dabei wird in verschiedenen historisch-medialen Konstellationen deutlich, wie und mit welchen Beweggründen Bilder an Geschichte geknüpft worden sind. Der Fall Ringier ermöglicht so zugleich eine praxeologische Reflexion über das Verhältnis von Fotografie, Archiv und Geschichte.

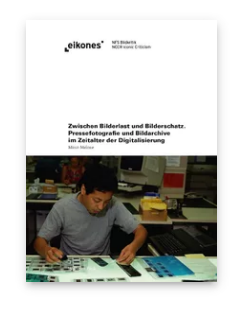

Published: o1 Jan 2018

Pages: 291 Seiten, $23 \mathrm{~s} / \mathrm{w}$ und 32 farb. Abb.

Subjects:

General, Media Studies

Publisher: Brill | Fink

Series: Eikones

E-Book (PDF)

ISBN: $978-3^{-}$

$8467-6272-1$

Price:

Paperback ISBN: $978-3^{-}$ 7705-6272-5

Price: 
Mirco Melone ist Fotohistoriker und Archivar. Er hat an der Universität Basel Geschichte studiert und für verschiedene öffentliche Archive und Museen gearbeitet. Von 2012 bis 2014 forschte er am NFS Bildkritik eikones zum Thema Bildarchive und Digitalisierung. Anschließend promovierte er an der Universität Zürich. Nun ist er als Wissenschaftlicher Archivar für das Staatsarchiv Basel-Landschaft tätig.

Please send your order to: Brockhaus/Commission Tel: +49(o)71 541327 9216 | E-Mail: brill@ $\underline{\text { brocom.de }}$

For questions please contact: Brill Deutschland GmbH Wollmarktstraße 115 | 33098 Paderborn | Germany Tel: +49 (o)5251 69975 o | E-Mail: sales@brill.com. 